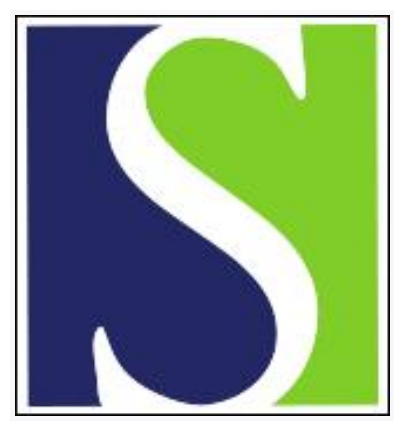

Scand J Work Environ Health 2009;35(5):394-396

https://doi.org/10.5271/sjweh.1343

Published online: 11 Aug 2009, Issue date: 00 Oct 2009

\title{
Perspectives of working life research
}

by Järvholm B, Albin M, Johansson G, Wadensjö E

Affiliation: Department of Public Health and Clinical Medicine, Umeå University, SE-901 85 Umeå, Sweden. Bengt.jarvholm@envmed.umu.se

The following article refers to this text: 2011;37(2):81-84

Key terms: discussion paper; prevention; productivity; research; wealth; working life; working life research; worklife; worklife research

This article in PubMed: www.ncbi.nlm.nih.gov/pubmed/19669072 


\title{
Perspectives of working life research
}

\author{
by Bengt Järvholm, MD, PhD, ${ }^{1}$ Maria Albin, MD, PhD, ${ }^{2}$ Gunn Johansson, PhD, ${ }^{3}$ Eskil Wadensjö, PhD ${ }^{4}$
}

\begin{abstract}
Järvholm B, Albin M, Johansson G, Wadensjö E. Perspectives of working life research. Scand J Work Environ Health. 2009;35(5):394-396.

We recently finished a position paper on Swedish working life research for the Swedish Council for Working Life and Social Research (1). An obvious question was the definition of "working life research". Searching the literature, we found a plethora of terms used to describe this area and lack of a generally accepted definition. It also became clear that the primary goals of such research varied widely between international organizations and governments. In this paper, our aim is to discuss the definition and goals of working life research.
\end{abstract}

Key terms discussion paper; prevention; productivity; wealth; worklife.

The classic objective in occupational health is to protect the worker from hazards in the workplace, ie, to protect the worker from being exposed to agents/conditions that may cause harm (eg, chemicals, vibrations, adverse organizational conditions). The groups most exposed to different risks in working life are young people, immigrant workers, and older workers. At the same time, it is very important that employment increases among those groups not least due to rapid ageing of the population in European countries. Research on these topics should address the functioning of the labor market and how it is related to general economic development. It is equally important to recognize that exposure to work hazards is higher among the self-employed and employees of small firms, and that these groups are increasing their share of employed workers. Focusing on occupational and organizational factors, in recent years, the workplace has been identified as an arena for the promotion of health and well-being. Some goals may be regarded as different aspects of public health. Some goals belong to other disciplines (eg, economics and psychology).

Both the World Health Organization (WHO) and the European Union (EU) stress the importance of good working conditions for economic wealth as well as health. A WHO commission on the social determinants of health recently concluded: "Employment and working conditions have powerful effects on health and health equity. When these are good, they can provide financial security, social status, personal development, social relations and self-esteem, and protection from physical and psychosocial hazards - each important for health. In addition to the direct health consequences of tackling work-related inequities, the health equity impacts will be even greater due to work's potential role in reducing gender, ethnic, racial, and other social inequities" (2). In a Resolution, the European Commission states that: "Quality at work has a considerable human, but also an economic dimension, and the Member States have acknowledged under the Lisbon Strategy that health and safety policy makes an important contribution to economic growth and employment" (3).

The Swedish government, in its recent governmental bill on research and innovation (4), focused on research that increases work-life participation. Good working conditions are important to improve the work ability of the population. The government also emphasizes the importance of working life research for welfare development. It wants to boost research in occupational health services (OHS) mainly in order to decrease sickness absence. The bill lists three types of research: basic, applied, and needs-driven. Working life research would consequently be needs-driven.

The Partnership for European Research in Occupational Safety and Health (PEROSH), a cooperation of

\footnotetext{
1 Occupational and Environmental Medicine, department of Public Health and Clinical Medicine, Umeå University, Umeå, Sweden.

2 Occupational and Environmental Medicine, Department of Laboratory Medicine, Lund University, Lund, Sweden.

3 Department of Psychology, Stockholm University, Stockholm, Sweden.

4 Swedish Institute for Social Research, Stockholm University, Stockholm, Sweden.
}

Correspondence to: Dr B Järvholm, Department of Public Health and Clinical Medicine, Umeå University, SE-901 85 Umeå, Sweden. [E-mail: bengt.jarvholm@envmed.umu.se] 
13 European institutes for occupational safety and health in 12 European countries, states its mission as: "research and development efforts for healthier, longer and more productive lives" (http://www.perosh.eu).

The term "well-being at work" was introduced by an EU project including six countries and is defined as: “... safe, healthy, and productive work in a well-led organization by competent workers and work communities who see their job as meaningful and rewarding, and see work as a factor that supports their life management." (5) This definition is well in line with the mission of PEROSH, but the focus in the six different countries varies; some focus on promoting health, others on promoting work ability, and others still on productivity.

The US research institute for occupational safety and health (NIOSH) focuses mainly on disease prevention and states its objective as "prevention of work-related injury and illness" (http://www.cdc.gov/niosh/about. html). The Canadian Centre for Occupational Health and Safety (CCOHS), a federal Canadian agency, states its vision as "eliminating all Canadian work-related illnesses and injuries" (http://forum05.ccohs.ca/about.html).

The Swedish government defines working life research as research on the working environment and the labor market, including labor legislation and work organization (1). The Swedish Council for Working Life and Social Research uses a similar definition.

This small survey of definitions indicates that, in Canada and the US, the focus is on the prevention of occupational diseases and injuries, while in Europe the present-day focus is more on productivity and wellbeing. There has been a downward trend in severe occupational injuries during recent decades in many countries and the change of focus could be regarded as an effect of that trend. However, the cost of occupational diseases and injuries is still very high. A European committee estimated it to be about $3 \%$ of GNP, which in Sweden would be around 100 billion SEK (about 10 billion euros) (1). The change of focus may depend on the understanding that working life research striving to promote health will, at the same time, promote productivity.

Thus, there may be several reasons why society needs high-quality working life research and these arguments may not contradict each other, but they may be, more or less, pronounced by different "users and supporters" of the research.

\section{A conceptual model}

The concept of health can have different meanings. A simplistic view regards it as the opposite of disease. In recent times, a more holistic view has been suggested in which good health means that a person can use and develop his or her human resources and achieve essential personal goals. It is, therefore, not surprising that the concept of occupational health has broadened. Figure 1 is a conceptual model describing the different objectives of working life research. Traditionally such research has aimed at preventing disease and injuries; there is a vast literature identifying risk factors (arrow B). A direct effect of work on health may be exemplified by work in non-smoking environments, eg, smoking was restricted early on in certain jobs both by enforcement and also by general attitudes in some occupational groups (eg, smoking behavior among chest physicians has, for a long time, been criticized by colleagues) (arrow C). Workplace anti-smoking campaigns and support programs for employees suffering from alcoholism are examples of how the occupational setting is used as an arena to promote health. However, there are far less examples of arrow $\mathrm{C}$ than arrow $\mathrm{B}$.

On the other hand, there are numerous studies showing that economic resources are associated with health (arrow E). Thus, the health-promoting effects of work may be mainly through arrows D and E. Research on work modifications through both physical and organizational measures may provide a basis for evidence-based promotion of work ability (arrow D). Selection into the work force and other aspects of the labor market (arrow A) are central aspects in psychological and economic research. Inclusion also of occupational and social medicine may provide a deeper understanding of the actual conditions which mediate the effect on health.

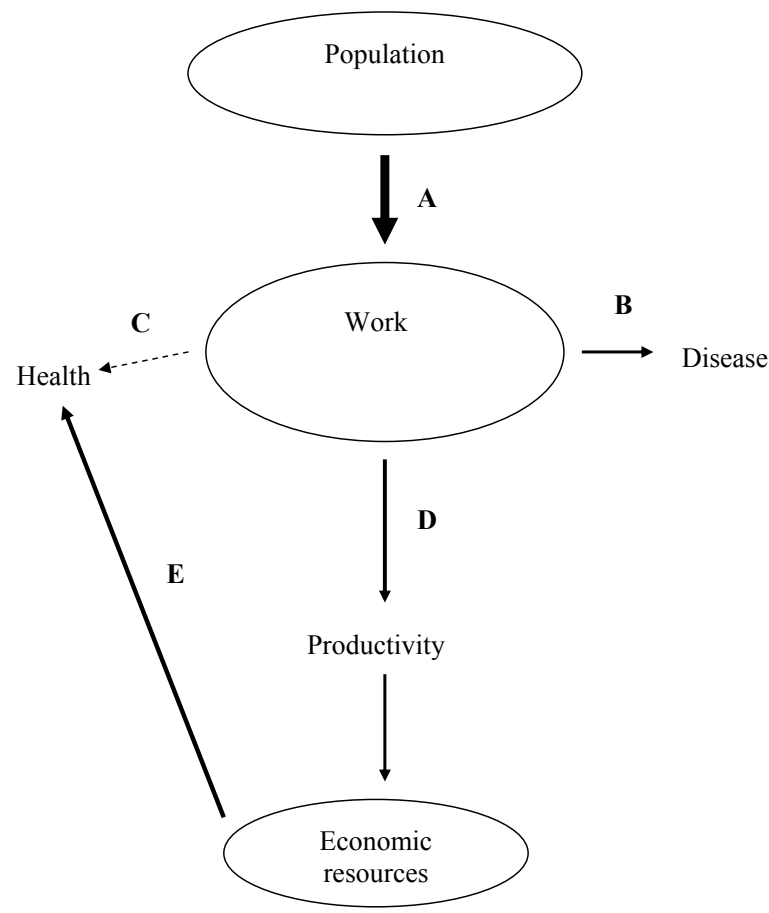

Figure 1. A conceptual model for working life research. 
Working life research uses a wide range of different methods and evolves from different scientific areas. The common denominator is that it could be defined as needs-driven. That does not contradict that it uses and develops basic and applied science. Some of the research belongs in the public health domain, some within behavioral science, and some in economics etc. The history of working life research is successful considering the improvement of some injuries and the eradication of some diseases. Such improvements do not counteract progress in productivity and wealth, and are well in line with the broad approach to public health and equity recently used by the WHO. We suggest a model integrating these aspects.

\section{References}

1. Swedish Council for working life and social research (FAS). Svensk arbetslivsforskning - en resurs för välfärd hälsa och tillväxt [Swedish research of worklife - a resource for welfare and growth]. Stockholm: FAS; 2009.

2. World Health Organization (WHO), Commission on Social Determinant of Health. Closing the gap in a generation: health equity through action on the social determinants of health [final report]. Geneva: WHO; 2008.

3. European Commission. Council resolution of 25 June 2007 on a new community strategy on health and safety at work (2007-2012). Brussels: European Commission; 2007. 2007/ C145/01.

4. Government Offices of Sweden. Government bill: a boost to research and Innovation. Stockholm: Government Offices of Sweden; 2008 [cited 22 May 2009]. Available from: http:// www.sweden.gov.se/sb/d/6949/a/115809

5. Anttonen H, Räsänen T. Well-being at work - new innovations and good practices. Helsinki: Finnish Institute of Occupational Health; 2009.

Received for publication: 26 June 2009 